\title{
PLURIUNIVERSOS: poesia popular, movência e distinção
}

Cristiane Moreira Cobra (DUC/SP)

\section{Introdução}

A autoridade para definir gêneros e tipologias literárias se dá num processo histórico-social gradativo que traz consigo inúmeras disputas entre grupos até a constituição de regras e critérios definitivos; como questiona FERREIRA (2010, p.34) a respeito de rótulos e designaçôes atribuídas às produçôes humanas "Quem detém os limites entre as coisas e o que nos fará, de fato, dizer com tanta certeza que a outra literatura, a 'não trivial', é que é a LITERATURA?". A poesia popular é parte da chamada cultura popular, se constituiu num processo histórico de diferenciação entre o oficial e o não oficial, e, conforme BURKE (2010, p.11), essa distinção originou a contraposição entre cultura erudita e cultura popular que acabou se constituindo como oposição não às elites, mas à cultura oficial, segundo BAKHTIN (2010); representando historicamente a transgressão dos limites, o contra oficial que existe em todos e não prioridade de algum grupo social. Ao longo dos estudos, certa visão romântica sobre o popular acabou se constituindo, tornou-se reducionista, esquecendo que a cultura popular é histórica, passa por transformaçôes no tempo; que a tradição é importante, mas o estilo individual também e que a cultura popular nunca foi monolítica nem homogênea, e sim que toda cultura é composta de subculturas que compóem um sistema de significados partilhados, uma faixa cultural na expressão de BOSI (1992, pp.308-345), simultaneamente as pessoas participam das faixas e partilham os significados da cultura em geral. 
MIRA (2014) considera cultura popular como próxima da ideia de folclore, mas também comenta sua relação com a cultura de massas e afirma que as cisóes conceituais não dão conta da realidade que é indissociável, aponta que no terceiro milênio ocorre a rearticulação de traços culturais locais com interesses da indústria do turismo e assim cultura popular passa a ser pensada também como um bom negócio; há uma confluência entre a ética do entretenimento e do consumo com o ethos festivo da cultura popular. MIRA (2014) reafirma que não há essência da cultura popular, nem de cultura nenhuma, na realidade trata-se de história, elementos recriados, modificados e perdidos; relaçôes de poder, dominação, resistência e acomodação; na mundialização da cultura vivemos um momento novo na história das apropriaçôes da cultura popular que associa tradição, raiz, patrimônio imaterial e diversidade cultural, situação que modifica, mas não necessariamente representa padronização da cultura ou resistência à globalização. Neste processo pós-moderno um novo padrão cultural se constitui, marcado pelo encurtamento das distâncias e pela aceleração do tempo, é um modo de vida mundial que atravessa as fronteiras dos Estados nacionais, mas não necessariamente uniformiza.

\section{Poesia/popular/es e seus pluriuniversos}

A trajetória da poesia popular, desde a Europa até o Brasil se deu em um longo processo histórico de difusão e criação, conforme pesquisa desenvolvida (COBRA, 2006); poetas nômades que contavam com livre locomoção, no regime feudal europeu, e assumiam as funçôes de verdadeiros jornalistas divulgadores das novidades, cantadores das aventureiras e heróicas bravuras de sua época, compunham narrativas populares, contrariavam o estabelecido e caracterizavam uma espécie de oposição à literatura oficial da Igreja que gerou uma produção cultural regional, transportada para o restante da Europa por três categorias de poetas andarilhos: os menestréis, os trovadores e os jograis. A poesia popular produzida no Brasil foi denominada por ABREU (1999) como literatura de folhetos nordestinos, definida pela pesquisadora como bastante codificada e muito diferente do cordel lusitano, se constituiu numa nova forma literária, a partir de cantorias e folhetos de fins do século XIX e início do século XX.

Opto aqui pela referência do objeto de estudo como poesia popular, apesar de considerar os resultados da pesquisa de ABREU (1999) e concordar sobre as especificidades dessa poesia brasileira, não a considero como exclusividade nordestina. Além disso, considero positivas as análises, já citadas, que apontam o popular como o não oficial, alargando a hipótese de que popular seria somente o produzido por camadas subalternas econômica e socialmente. Considero que tais análises contribuem para 
a percepção da constituição das tais disposições duráveis, denominada habitus por BOURDIEU.

A questão desta pesquisa tomou por objeto a poesia popular brasileira, com o objetivo de compreender os processos de institucionalização e distinção, produção e reprodução deste gênero, propondo um recorte analítico a partir de dois poetas atuais e atuantes e de seus distintos contextos. Como se deram os processos de reconhecimento e legitimação da poesia popular na trajetória destes poetas? Se existiram quais foram as inovaçôes efetivadas por eles? É possível perceber a constituição de universos poéticos plurais que constituem o campo da poesia popular?

Moreira de Acopiara ${ }^{1}$ é codinome usual de Manoel Moreira Júnior, nascido em 1961 no Nordeste brasileiro, em Acopiara no Ceará, mais precisamente, mas que desde 1983 vive em São Paulo. Como as apresentaçóes de diversos de seus livros dizem, embrenhado no mundo das letras desde cedo, Moreira é poeta nordestino radicado em Diadema. Os primeiros livros de Moreira foram publicados no início da década de 1990, ainda por editoras do Ceará, sendo hoje um autor reconhecido que ultrapassou os 100 folhetos de cordel, já gravou dois CDs e publicou mais de dez livros, sendo os atuais publicados em diferentes editoras de São Paulo. O poeta Moreira de Acopiara lançou um folheto em 2006, chamado "O beabá do cordel e do repente", que foi posteriormente modificado, retiradas algumas estrofes, acrescido de novas informaçóes, intitulado "Cordel em arte e verso" e lançado como livro em 2010. Este livro foi considerado altamente recomendável pela FNLIJ e na primeira versão como folheto trazia dois poemas, o primeiro chamado $O$ beabá do cordel e o segundo $O$ beabá do repente, todo ilustrado com xilogravuras de Marcelo Soares. O primeiro poema, na versão publicada em folheto, contava na primeira edição com 51 estrofes compostas em sextilhas e resumia a história e a migração do cordel, relatando de que maneira e por quais caminhos esse gênero prosseguiu até chegar aos nossos dias. Moreira de Acopiara é autor de inúmeros folhetos e livros de poesia popular, já teve poemas seus musicados por artistas da TV como Jackson Antunes, concede entrevistas para programas de televisão (TV Cultura, etc), jornais impressos locais (ABC paulista) e apresenta regularmente um programa de rádio; já foi citado em trabalhos acadêmicos, além de participar presencialmente de eventos pelo Brasil, principalmente na grande São Paulo e ABC paulista. Ele divulga seus trabalhos por email e também tem perfil em redes sociais; interessa notar que Moreira de Acopiara, sem abandonar o verso, toma para si a tarefa de fazer história e de ajuizar as normas do bom cordel, numa espécie de "arte poética"; o que supóe o reconhecimento do valor que o gênero já havia obtido nas letras brasileiras, como fonte de cultura autêntica. Mostra-se assim inclinado a ser um intelectual da prática letrada que seus antecessores faziam por fazer. 
Ditão Virgílio ${ }^{2}$ vive distante do sertão nordestino, nasceu e mora em São Luiz do Paraitinga, interior de São Paulo, Patativa do Assaré também compõe seu panteão de poetas referência, já participou de concursos que referendavam seu modelo, conhece sua obra e reconhece elementos semelhantes com suas próprias características poéticas, como a linguagem matuta e a origem humilde, entre outras. Conforme o prefácio do primeiro livro do próprio Ditão Virgílio, escrito por Jô Amado, ele é um poeta da roça, caipira que mantém hábitos simples como tomar café, prosear com bichos e outros elementos da natureza, falar com sotaque bem típico. E como eu mesma pude observar, mesmo antes, e agora ainda mais atenta nestes anos de pesquisa participante, Ditão faz questão de andar de botina, jeans, camisa xadrez, com seu chapéu e jamais perder uma boa prosa na praça da Igreja Matriz em São Luiz do Paraitinga. Seus poemas, sempre chamados de "Estórias de uma perna só" foram inicialmente publicados em pequenos livretos do tipo cordel e eram assim comercializados nas lojinhas do Mercado Municipal da cidade e também em outros pontos comerciais de Sáo Luiz do Paraitinga. Apenas em 2010 ocorreu a possibilidade de Ditão editar seus versos na forma de livro, através do PROAC, Programa de Ação Cultural do Estado de São Paulo, que possibilitou o projeto apoiado pelo Governo do Estado. Na contra capa deste primeiro livro há uma referência ao cordel caipira, categorização que me chamou a atenção e que pretendo discutir posteriormente; o livro apresenta histórias em versos, usa linguagem caipira, grafando conforme o sotaque típico da região e apresenta em sua orelha uma relação entre o nheengatu, língua geral indígena do início da colonização, e o sotaque caipira do Vale do Paraíba. Dos vinte poemas contidos no livro, dezoito são sobre o Saci, exatamente daí a referência às "Estórias de uma perna só". Ditão lançou também em 2011 um livro em prosa com lendas tradicionais de sua cidade, com o título de $O$ real e o imaginário o livro narra as aventuras de dois personagens viajantes que encontram indígenas, quilombos e outras surpresas às margens do rio Paraitinga. Nas últimas páginas deste livro Ditão também reproduz versos simples sobre a famosa e tradicional Festa do Divino e acrescenta ainda uma ilustração do Saci, além da própria marcação das páginas do livro contar com ilustrações miniaturas de sacizinhos e o número das páginas ficar dentro de um cachimbo, assim como em seu primeiro livro.

$\mathrm{Na}$ orelha deste segundo livro Ditão é apresentado por Alfredo Fontes "como o mais simples, puro e sincero arrebatador" de lendas do folclore brasileiro e do Vale do Paraíba que segundo o comentarista merece toda a atenção dos leitores, apreciadores e cultuadores de lendas brasileiras. Ditão Virgílio é autor de inúmeros folhetos e livros de poesia popular, também concede entrevistas, inclusive já participou do programa PANNICO na Band, foi entrevistado por diversos jornais impressos e televisivos locais (Vale do Paraíba), compóe cançóes juninas e participa de festivais anuais em sua cidade, 
São Luiz do Paraitinga; também tem perfil em redes sociais e já foi citado em trabalhos acadêmicos, além de participar presencialmente de eventos pelo Brasil, principalmente no grande Vale do Paraíba paulista.

O trânsito do gênero se faz hoje tanto pelo espaço real quanto pelo virtual, o tempo acelerado da sociedade contemporânea atinge as produçóes culturais, a poesia popular se constituiu como gênero numa longa trajetória desde a Europa até o Brasil se considerarmos tudo que já foi citado anteriormente. A poesia popular pode ser pensada como uma poética movente, retirante, nômade, andarilha, peregrina, transeunte que percorre distâncias pelos subterfúgios da oralidade e, vez ou outra, encarna e se materializa em folhetos, livros, CDs, DVDs ou outras formas de registro, cada forma de suporte material limita e ao mesmo tempo amplia as condições de expansão desta poética, que persiste recheada de marcas da oralidade e de elementos performáticos.

Ditão Virgílio e Moreira de Acopiara tem em comum a característica de representantes da chamada poesia popular, são poetas que surgiram duma matriz oral, declamando com maestria em espaços públicos, festas populares, saraus familiares e rodas de conversa em feiras, mercados, praças públicas. Estabelecido seu reconhecimento social pela habilidade de versificação oral e memorização extensa foram conquistando espaço e ampliando seu campo de atuação do oral para o escrito, publicando folhetos de cordel e, posteriormente, livros; hoje seus horizontes se ampliam ainda mais e já divulgam seu perfil, sua agenda de apresentação e trechos de sua obra em redes sociais, já tem poemas musicados participando de festivais e gravados em CDs, concedem entrevistas para canais televisivos locais e nacionais.

ZUMTHOR (1985) reafirma que houve épocas de interesse quase que exclusivo de historiadores e pesquisadores pela escrita; mas ele destaca a importância da voz na conservação das sociedades humanas, diz que as tradiçóes orais, assim como o mundo da escrita, compóem redes de intercâmbios vocais vinculados aos comportamentos regrados, com finalidade de manutenção de certa percepção de vida. Ditão Virgílio e Moreira de Acopiara são, entretanto, exemplos de poetas que têm como raiz a oralidade, mas que também se constituem na escrita, e que hoje ultrapassam esses limites assumindo-se como poetas multimídia de oralidade mediatizada. ZUMTHOR (1985) salienta que a oposição entre oral e escrito possui caráter categorial e não histórico, isto é, conviveram sempre nas sociedades letradas de diversas épocas homens da voz e homens da escritura. Ele esboça uma tipologia geral das situaçóes de oralidade no mundo, reduzindo a diversidade a quatro espécies: oralidade primária - existe sem nenhum contato com a escrita (comunidades arcaicas, culturas 'primitivas' em vias de desaparecer); oralidade mista - coexiste com a escrita num contexto social no qual a 
influência da escrita é de carater parcial; oralidade secundária - existe nas realidades em que predomina a escrita; oralidade mediatizada - existe através da rádio, do disco e de outros meios de comunicação;

Em sociedades que coexistem língua nacional/escritura oficial X línguas locais/ dialetos surgem tensóes entre a literatura nacional escrita e uma poesia oral ligada a fala regional e regionalismos, gerando assim variedade literária. Há distanciamentos entre a obra de Ditão e Moreira para além da proveniência diversa dos poetas, diversa principalmente geograficamente, mas também diversa no seu fazer poético. Moreira de Acopiara, nordestino radicado no ABC paulista há mais de trinta anos é, portanto, um cidadão metropolitano e disputa por espaço no mercado editorial da capital, além de transitar por outros Estados do país divulgando seu trabalho, conhecendo pessoas e instituiçóes, nesse trânsito constituiu a percepção de que sua poesia tem como base as regras do cordel, a saber, a rima, a métrica e a oração, além de primar pela gramática e ortografia estabelecidas pela norma culta. Já Ditão Virgílio, nativo de São Luiz do Paraitinga é um caipira que constituiu sua poesia inspirado pelas novelas de rádio, publica com recursos próprios e, mais atualmente, com apoio de programas governamentais que o reconhecem por sua linguagem matuta que desconsidera a norma culta e pode ser classificada como variação linguística, regionalismo ou outros rótulos, pelo fato de usar termos típicos da linguagem caipira e escrevê-los da forma como diz. Ditão hoje também transita pelo país divulgando seu trabalho, sua cultura e sua poética denominada por alguns e por ele mesmo de cordel caipira.

ZUMTHOR (1985) afirma que colocar por escrito poemas de tradição oral não coloca fim a essa poesia oral, ao contrário, pode produzir-se um desdobramento; desde sempre é porosa a fronteira entre oral e escrito de acordo com ele e os poetas orais são influenciados por procedimentos estilísticos ou tendências temáticas pertencentes a tradição escrita. A escrita tem valores particulares e a voz também implanta e promove outros valores que no momento da execução se integram ao sentido do texto transmitido, enriquecendo e transformando esse sentido... A voz transborda a palavra. Entre oralidade e escrita se encontram hoje as obras tanto de Ditão quanto de Moreira, são voz e corpo em performance quando de suas apresentaçôes presenciais, são únicos nestes momentos, mas podem ser reproduzidos tecnologicamente quando divulgam sua obra em CD, DVD ou pela internet em vídeos e áudios; além disso, desdobram-se em texto escrito nos folhetos, nos livros e na divulgação pela internet que exige do público a leitura, a decifração pela linguagem escrita que difere do uso da pura audição para ouvir poemas declamados ou musicados ou ainda da visão/audição para assistir vídeos de apresentaçôes poéticas em shows. 
Processos culturais globalizantes relacionados às práticas locais de registro da produção popular têm se efetivado em tentativas de legitimação e reconhecimento das práticas populares por parte de órgãos oficiais como o IPHAN visando preservação do patrimônio, tombamentos e regulamentaçóes, registros e inventários. Conforme o sítio do IPHAN, os planos, registros e inventários são instrumentos de preservação do patrimônio cultural e artístico brasileiro e tais açôes são executadas a partir de um diagnóstico prévio de avaliação do patrimônio que considera os diversos aspectos a ele relacionados, como classificação e valoração, constituindo formas de conhecimento e pesquisa. Na virada do milênio, através do Decreto no 3.551, o IPHAN instituiu o Registro de Bens Culturais de Natureza Imaterial e definiu um programa para tais bens; neste momento teve início o processo de reconhecimento de bens culturais como patrimônio imaterial, instituiu-se o registro e o compromisso do Estado de inventariar, documentar, produzir conhecimento e apoiar a dinâmica dessas práticas socioculturais.

O sítio do IPHAN informa que desde então registra saberes, celebraçôes, rituais e formas de expressão, além dos espaços onde tais práticas se desenvolvem. Pelo Decreto $\mathrm{n}^{\circ} 3.551 / 2000$ foram criados ainda os diferentes Livros de Registro que definem distintos domínios na composição daquilo que é o imaterial, surgindo assim categorias para esses livros: Saberes - conhecimentos e modos de fazer enraizados no cotidiano das comunidades; Formas de expressão - manifestaçóes literárias, musicais, pláticas, cênicas e lúdicas; Celebraçôes - rituais e festas que marcam a vivência coletiva do trabalho, da religiosidade, do entretenimento e de outras práticas da vida social; Lugares - mercados, feiras, santuários, praças e demais espaços onde se concentram e se reproduzem práticas culturais coletivas. Além desse diferentes livros, se instituíram regras para o envio de pedidos de registro que devem ser seguidas, conforme os artigos 2 a 4 da Resoluçáo 001/06.

O Instituto do Patrimônio Histórico e Artístico Nacional promoveu em 2012, na sede da Fundação Casa de Rui Barbosa, no Rio de Janeiro, uma reunião técnica sobre a "Literatura de Cordel", da qual participaram especialistas e instituiçôes ligadas ao assunto; tal reunião decorreu do pedido de Registro da Literatura de Cordel como patrimônio cultural de natureza imaterial em 2010, apresentado pela a Academia Brasileira de Literatura de Cordel - ABLC. O IPHAN julgou pertinente o pedido que passou pelo Departamento de Patrimônio Imaterial e pela Câmara de Patrimônio Imaterial do Conselho Consultivo do Patrimônio Cultural; e assim teve início o processo de Registro que depois passou à fase de instruçáo técnica, sendo produzidas e sistematizadas informaçôes sobre o bem cultural, com vistas ao seu reconhecimento e titulaçáo como Patrimônio Cultural do Brasil. Nesta reunião técnica discutiu-se e delimitou-se o objeto do 
Registro, seu território, os bens culturais associados, entre outros aspectos significativos, assim como se definiu o plano de trabalho que orientou pesquisas e demais atividades. Algumas proposições práticas resultantes da reunião foram a realização de mapeamento da documentação, instituiçôes, especialistas, artistas e de contatos sobre o tema; a criação de uma rede de instituiçôes detentoras de acervos; a consolidação de acervos e bibliografia temática; e o intercâmbio de folhetos de cordel entre as mesmas. Sugeriu-se, ainda, o encaminhamento de açóes específicas com vistas ao tombamento dos acervos de folhetos no Brasil. Além destas iniciativas, para a instrução do processo de Registro da Literatura de Cordel, deu-se início ao levantamento, pesquisa e documentação das formas orais e escritas relacionadas à mesma, tomando-se como base territorial cinco núcleos focais pré-definidos, abrangendo treze estados brasileiros. Nestes polos seriam realizados encontros regionais ampliados sobre o tema do cordel, com os objetivos de informar os praticantes dessa arte e de seu universo associado sobre o processo de Registro em andamento, envolvê-los nos procedimentos exigidos, esclarecer sobre as consequências desse ato, além de articular parcerias, o primeiro encontro regional aconteceu no mesmo ano de 2012, na cidade de Campina Grande, Paraíba.

A Academia Brasileira de Literatura de Cordel foi fundada no dia 7 de setembro de 1988 por três cordelistas, o presidente Gonçalo Ferreira da Silva, o vice Apolônio Alves dos Santos e o diretor cultural Hélio Dutra; eles realizaram suas primeiras reunióes na sala emprestada por um candidato político, sendo uma instituição errante por certo período, conforme relatos do sítio da própria ABLC. Segundo o sítio da ABLC e a lista de poetas que ocupam suas cadeiras Moreira de Acopiara ocupa a quarta cadeira da ABLC e muito se orgulha disso, como afirma em apresentaçóes públicas e também reafirmou em entrevista específica concedida para pesquisa, por conta disso, consta no sítio da ABLC um detalhamento com foto e pequeno texto específico sobre ele, assim como sobre cada um de seus membros. No Estatuto da ABLC, em seu artigo $5^{\circ}$, fica estabelecida a forma como ocorre a admissão de novos membros quando surge cadeira vaga, por falecimento de um dos acadêmicos ou por outro motivo; de acordo com o sítio a admissão ocorre através de votação em escrutínio secreto, com a maioria da diretoria em exercício.

O poeta Moreira de Acopiara é membro oficial da ABLC, reconhece seu estatuto e as normas estabelecidas, conforme o conceito de habitus, proposto por BOURDIEU (2004) podemos pensar que a constituição de Moreira toma por base a identificação com o papel do poeta popular, a reprodução de certas disposiçóes sociais duráveis; o compromisso com a métrica e a rima padronizadas são exigências das formas escritas elaboradas ao longo da história da poesia popular no Brasil. Em relação a formas ar- 
tísticas e literárias reconhecidas existe um habitus estabelecido, maneiras de pensar, reconhecer e agir sobre objetos artísticos; e é este habitus que se manifesta a respeito também da poesia popular, quando os próprios poetas reproduzem instituiçóes como Academias de Letras, visando reconhecimento e legitimidade social.

BOURDIEU (2004) afirma que toda prática é produto de uma relação dialética entre a situação e o habitus (sistema de disposiçóes duráveis que serve de matriz para percepçôes, avaliaçóes e açôes), e, portanto, a prática produz esquemas que sáo reaplicados em outras situaçôes dadas, por transferência analógica. Criar Academias de Literatura de Cordel revela a contradição vivida por parte dos poetas populares neste processo, com a reaplicação de esquemas socialmente aprendidos com a classe dominante para legitimação de suas produçôes criativas; podemos pensar a poesia popular como um gênero em construção que acaba por constituir um campo e um habitus próprio, derivado de seu ambiente social de reprodução de práticas orais e letradas. Os poetas encontram-se numa situação de duplo vínculo, aquele que o liga à tradição oral imemorial e aquele que o atrai para operaçôes mais ambiciosas no ambiente das letras em escala nacional, percebem sua importância não apenas "no sertáo", mas também na naçâo letrada. As Academias de letras nasceram no século XVII com o objetivo de "policiar" as letras, tiveram como propósito inicial produzir dicionários, gramáticas e estabelecer padróes literários, instituindo um cânone; forjando um habitus que seriam as tais disposiçôes duráveis, matrizes de percepçôes, avaliaçôes e ações. Mas as iniciais Academias sucumbiram no fim do século XIX, quando sua autoridade de ajuizar e normatizar as práticas letradas foi fortemente questionada, pois o campo literário estabeleceu que a regra da arte é não ter regra, a anomia é a regra da arte segundo BOURDIEU (1996). Este dilema é vivido hoje pelos poetas populares, pois vistos de fora de seu próprio campo, eles expressam a liberdade do povo contra as imposiçóes da cultura letrada "policiada", no entanto, para preservar o seu carisma dentro de seu próprio campo, reconhecido pela cultura legítima, ele ainda se vê na obrigação de "policiar" a sua arte, via instituições como a ABLC.

O habitus fornece princípios, categorias de juízo e ação, que advém da sociedade e são partilhadas por todos que se sujeitam às mesmas condiçôes; mas cada pessoa, com sua localização e trajetória única no mundo, internaliza uma combinação inigualável de esquemas. Portanto, a originalidade e criatividade dos poetas populares ocorre dentro de categorias de juízo e ação sociais, partilhadas e constituídas conforme as condições dadas pela sociedade. Esse habitus é estruturado e estruturante, os indivíduos são, portanto, seres carnais, habitados pela necessidade histórica, que se relacionam com o mundo por cumplicidade ontológica e conluio implícito, fomentados por categorias 
comuns de percepção e apreciação; trata-se de um conjunto estratificado e dinâmico de disposiçôes que registram, armazenam e prolongam a influência de ambientes diversos encontrados sucessivamente na vida das pessoas.

\section{Aspectos conclusivos, em tese}

Sendo membros da sociedade brasileira, falantes da língua nacional, formados nessa cultura nacional e constituídos pelos valores sedimentados aqui, os poetas populares podem ser pensados como seres em conflito, eles eram produtores da heterodoxia e ficavam acanhados diante da cultura letrada ortodoxa, porém, sendo membros da cultura e da sociedade nacional eles reconhecem a cultura letrada e, dada a sua condição a legitimam, na nova situação, acabando alguns por acreditar que a condição para a sua legitimação seria aderir à ortodoxia.

O discurso atual de patrimonialização segue a mesma lógica, necessita de critérios para saber quem merece o selo (e a verba) de manifestação autêntica e estabelece normas rígidas em defesa da poesia popular, seguindo padróes estabelecidos por instituiçóes como ABLC, acaba por ser a atitude da maioria dos poetas populares, visando estabelecer-se como patrimônio cultural legítimo, deixando de compor a heterodoxia e passando a ortodoxia; não significando isso entretanto que todos os poetas populares sigam esse modelo e o defendam.

A existência de 'falhas' e momentos críticos no habitus é o que possibilita inovação social e mudança, o poeta e contador de causo Ditão Virgílio começou a ampliar seu espaço de atuação para além dos limites do Vale do Paraíba paulista há algumas décadas, mas após o ano de 2010 com a publicação de seu primeiro livro Estórias de uma perna só, projeto apoiado pelo PROAC - Programa de Ação Cultural do Estado de São Paulo, da Secretaria de Estado da Cultura, isto se deu de forma mais acentuada; esta primeira publicação em livro contou com a seleção de vinte poemas, antes já publicados em folhetos de cordel, com ilustraçóes bastante originais, baseadas em fotos de cabaças pintadas com motivos folclóricos e mitológicos típicos da cultura caipira, feitas por outro luizense, chamado Geraldo Tartaruga. O livro conta ainda com um glossário próprio que esclarece certos termos de uso do caipira, com mais de sessenta palavras com grafia bem peculiar e de uso pouco comum em regióes não caipiras; e na segunda folha da publicação há uma foto do autor com uma epígrafe advertência "Não falo errado, apenas diferente!!!". O cordel caipira, assim intitulado pelo próprio Ditão desde os folhetos, não segue os moldes estabelecidos pela ABLC, os padróes de métrica, rima e oração definidores de 'bons' poetas de cordel, nem sabe da existência desta instituição 
e a própria Academia desconhece por completo o cordel caipira de Ditão Virgílio; ele escreve da forma que fala, por conta de seu habitus caipira. Num processo semelhante ao que ocorreu em outros períodos, épocas e lugares, a cultura oficial e seus órgáos legitimadores têm atualmente valorizado características culturais de grupos isolados, considerados pelo Estado Nacional como 'puros', representantes da 'essência nacional/ local', e, por conta disso, ser caipira se tornou uma marca identitária de reconhecimento social.

$\mathrm{Na}$ poesia popular existem categorias de percepção e apreciação que geraram princípios visando organizar e classificar obras poéticas, condutas esperadas para poetas populares, um esquema constituído e estabelecido que hoje pode se considerar esteja corporificado em instituiçôes como ABLC; entretanto como o próprio BOURDIEU afirma, a prática humana é marcada por intenção ativa e inventiva, há disposiçóes socialmente construídas e duráveis, mas que também se modificam ao longo do tempo.

Assim é possível reconhecer a existência de universos plurais, pluralidade de lógicas de diferentes 'mundos', lugares onde se constroem sensos comuns, lugares-comuns, sistemas não redutíveis uns aos outros; a estratégia é a orientação prática, não calculada, nem consciente ou mecanicamente determinada, mas fruto do senso de honra, essa lógica da prática e, no caso da poesia popular, penso que se constituíram estratégias diversas pelo Brasil, conforme as conjunturas regionais, locais, foram se construindo; e por conta disso considero a possibilidade de pluriuniversos, como variaçóes na poética popular de raízes orais e performáticas. Neste campo Moreira e Ditáo representam a contraditoriedade do real, a fissura que permite 'mudanças de habitus', analisá-los exige inversão dos valores que demarcaram historicamente centro e periferia da literatura brasileira, como sugerem BUENO, SALES e AUGUSTI (Orgs., 2013) em consonância com FERREIRA (2010) ao investigarem linhas da tradiçáo literária brasileira que situam dentro ou fora do cânone diversas experiências literárias.

\section{$\operatorname{son} 2$}

\section{NOTAS}

1 Obras consultadas:

ACOPIARA, Moreira de. Livro de bolso. Diadema/SP: Ferrari Editora. Secretaria de Cultura de Diadema e Prefeitura Municipal de Acopiara. ACOPIARA, Moreira de. Cordel em arte e versos. Xilogravuras de Erivaldo Ferreira da Silva. São Paulo: Duna Dueto: Acatu, 2008.

2 Obras consultadas:

VIRGÍLIO, Ditão. Estórias de uma perna só. São Luiz do Paraitinga/SP: Edição do autor, 2010. 
VIRGÍLIO, Ditão. O real e o imaginário: Lendas. São Luiz do Paraitinga/SP: Edição do autor, 2011.

\section{REFERÊNCIAS}

ABREU, Márcia de. Histórias de cordéis e folhetos. Campinas: Mercado das Letras/Associação de Leitura do Brasil, 1999.

BOURDIEU, Pierre. As regras da arte: gênese e estrutura do campo literário. Trad. Maria Lucia Machado. São Paulo: Companhia das Letras, 1996.

BOURDIEU, Pierre. Coisas ditas. (Trad.: Cássia R. da Silveira e Denise Moreno Pegorim; Rev.: Paula Montero) São Paulo: Editora Brasiliense, 2004.

BUENO, Luís e outros (Orgs.). A tradição literária brasileira: entre a periferia e o centro. Chapecó: Argos, 2013.

COBRA, Cristiane Moreira. Patativa do Assaré: uma hermenêutica criativa, a reinvenção da religiosidade na nação semi-árida. Dissertação de Mestrado defendida no PEPG em Ciências da Religião-PUC/ SP, 2006.

BAKHTIN, Mikhail. A cultura popular na Idade Média e no Renascimento. O contexto de François Rabelais. Tradução de Yara Frateschi Vieira. São Pailo: HUCITEC, 2010.

BOSI, Alfredo. Cultura brasileira e culturas brasileiras. In.: Dialética da colonização. São Paulo: Cia das Letras, 1992.

BURKE, Peter. Cultura popular na Idade Moderna: Europa 1500-1800. Tradução Denise Bottmann. São Paulo: Companhia das Letras, 2010.

FERREIRA, Jerusa Pires. Cultura das Bordas: Edição, Comunicação, Leitura. Cotia, SP: Ateliê Editorial, 2010.

HABITUS. Revista do Instituto Goiano de Pré-história e Antropologia. Editora da Universidade Católica de Goiás: Goiânia, v.2, n.1, pp.11-18,jan/jun 2004.

HALL, Stuart. Identidade Cultural na Pós-Modernidade. Tradução: Tomás Tadeu da Silva e Guacira Lopes Louro, DP\&A Editora,

MIRA, Maria Celeste. Entre a beleza do morto e a cultura viva: mediadores da cultura popular na Sáo Paulo da virada do milênio. Tese apresentada para obtenção do título de livre-docente em Antropologia pela Pontifícia Universidade Católica de São Paulo, 2014.

ZUMTHOR, Paul. Permanencia de la voz. In.: Revista El correo: uma ventana abierta al mundo. Agosto, No 8, año XXXVIII, ISSN 0304-310 X, UNESCO/PARIS: 1985.

http://portal.iphan.gov.br/portal/montarDetalheConteudo.do?id=16585\&sigla=Noticia\&retorno=detalheNoticia Acesso em 06 de junho de 2014

http://www.ablc.com.br/aablc.html acesso em 21 de agosto de 2013

\section{Resumo}

O objetivo desta pesquisa é compreender a poesia popular e seus processos de produção e institucionalização, através da obra de dois poetas atuais e atuantes: Moreira de Acopiara, nascido em Acopiara, sertão central do Ceará, radicado em Diadema, membro da ABLC, autor de dez livros e mais de cem folhetos de cordel; e Ditão Virgílio, nascido em São Luiz do Paraitinga, reduto caipira do interior de São Paulo, autor de vários folhetos e alguns livros. Tais poetas expressam sua poética de pontos de vista culturais distintos, sendo a memória e a oralidade elementos comuns de suas 
práticas. A pesquisa envolveu etnografia, análise de trajetória, entrevistas, observação participante e análise textual; observaram-se processos de distinção das produçóes populares, via instituiçóes oficiais como IPHAN e ABLC, com variáveis formas de atuação e reação dos próprios poetas; além de movências decorrentes de situaçóes de oralidade secundária meditatizada, poéticas como desdobramentos de fronteiras invisíveis entre oral e escrito que constituem pluriuniversos.

\section{Abstract}

The aim of this study is to understand a popular poetry and its creative and constitutive processes by means of two contemporary poets, Moreira de Acopiara and Ditão Virgílio. These poets express their poetics from the different cultural points of view while their common points are memory and oral practices. This study involves ethnography, interviews, observation and textual analysis.

Cristiane Moreira Cobra é Doutoranda no Programa de Estudos Pós-Graduados em Ciências Sociais da Pontifícia, Universidade Católica de São Paulo - Bolsista Taxa Capes. cristiane_cobra@yahoo.com.br 